\title{
CJPS
}

\author{
Iryna Pavlenko
}

University of Warsaw, Poland

\section{ENERGY SECURITY IN THE EUROPEAN UNION ${ }^{1}$}

\begin{abstract}
The aim of the article is to present a practical and methodological approach to assessing the energy security of European countries, with particular focus on states with coal-dependent energy systems and on finding balance between ensuring energy security, diversification of energy resources and environmental protection. As energy security means technically reliable, stable, cost-effective and environmentally balanced supply of energy resources to satisfy the needs of the economy and the population, the author proposes an indicator that takes into consideration different components, and can be a helpful tool in designing energy policies. The article also discusses using the energy potential of closed coal mines.
\end{abstract}

\section{Key words}

European Union, state's energy security, assessment of energy reliability, state's energy security indices

In the $21^{\text {st }}$ century a main goal for any country (apart from preserving territorial integrity and state independence) is economic and energy security and stability. The purpose of this article is to develop methodological and practical approaches to assessing the energy reliability of European Union countries with regard to coal mining. It is thus necessary to develop indicators of energy reliability that

1 The text was financed under the Minister of Science and Higher Education's program "DIALOG” for 2019-2021. 
are coefficients characterizing the availability of state's own energy resources and its economic situation as well as the reliability of its energy-consuming infrastructure (Commission of the European Communities, 2006).

\section{Literature overview}

Considering modern concepts of energy security, it should be emphasized that ensuring it is the duty not only of the fuel and energy complex, but also of the state itself. Kozachenko, Trifonova, and Heywood argue in their works that limiting the demand for primary energy resources through introducing energysaving policies can lead to chaos on the energy market. According to Astakhov, Dikolenko, and Kharchenko, industrial production is subject to a certain energy rhythm, due to the relationship between the gross domestic product and the volume of consumed products. This relationship in the long run is non-linear and forms under the influence of the laws governing the development of an industrial society. As a result, a simple extrapolation of a country's energy needs, based on specific trends, usually produces false results. This, incidentally, is evidenced by the fate of the forecasts developed on the eve of the energy crisis of 1973-1974. Meanwhile, Bravar, Morgan, Melnik, and Stenbacka call for a more in-depth study of the factors that shape and ensure the economic and energy reliability of countries in the $21^{\text {st }}$ century.

Available literature offers numerous analyses of the condition of energy systems in European countries. Although this research has significantly contributed to the development of theoretical and practical foundations of energy independence, a number of tasks of conceptual and methodological nature have not been fully resolved yet. A particularly important one involves formulating the guidelines for managing the sustainable functioning of elements of energy systems in European countries (especially coal mining) including methodological provisions for assessing the level of sustainability of their functioning and for improving the energy stability management system. In addition, an appropriate quantitative assessment mechanism is also needed to ensure that decision-makers are able to achieve a balanced relationship between the sustainability level of the country's energy sector and the costs of diversifying the corresponding industries.

The primary factor in energy security is the limited amount of natural resources on the planet, and the varying degree to which they are accessible to individual states. As a result, there is a constant threat of intensification of the economic and political struggle for the use of these resources. The global 
competition of individual producers in the world market tends to develop into competition of state economies - e.g. when areas of national interests are declared. Raw materials have been, remain and will continue to be the most important tool of political and military pressure. For its own economic security, a state must constantly implement legal, economic and administrative measures aimed at protecting its national interests, while relying on a long-term strategy. Global strategic goals are achieved by pursuing economic policy and, above all, by implementing various targeted programs based on scenarios of the developments likely to occur in all state and social spheres.

\section{Methodology and determinants of the energy security assessment of European countries}

The study aims to analyze the directions in which environmental standards are evolving and the priority given to them; it also focuses on the effective territorial distribution of industries, forecasting the consequences of economic activity and other measures that will further determine the conditions for conducting business activities of individual enterprises. It is noted that one of the major shortcomings of economic activity is decision-makers' inability or unwillingness to foresee the long-term consequences of the impact these factors have on nature.

Elimination of these shortcomings should improve the economic policy of environmental management. Thus, a comprehensive mechanism would be formed for influencing the nature users' economy in order to generate motivation for rational nature management with the following options of administrative regulation: permission, restriction, and ban.

The indicated characteristics of rational environmental management policy are very relevant for ensuring sustainable development of a society; however, most of influence instruments are directed at enterprises, which are defined as direct nature users (consume a natural resource) and at the same time are environmental polluters. If they fail to take measures to prevent damage to the environment, they should bear full responsibility for ecological and economic efficiency of their operations.

Every country constitutes a system, which at any given moment has certain reserves. These reserves can be divided into technological and organizational ones, which in many cases are quite substantial. Reserves of a country are, first of all, reserves of infrastructure. Barring accidents and emergency situations, there are practically no cases when individual production systems within state economy fail. A similar analysis can be made for any other area (such as transport, heavy 
industry etc.) and it will lead to the same result, but the negative impact of running out of reserves may not be as direct as in the case of energy reliability, and restoration of the reserve will be less complicated and not so capital-consuming.

It is methodologically obvious that the state of the country's reserves, especially with regard to the main production processes, directly affects the energy consumption. This requires, first of all, an objective solution to the most complex and most important issue, namely: which category should be assigned to each European country in terms of their natural energy resources. There have been numerous attempts to resolve this issue in a variety of ways - a difficult task as a country is a complex system shaped by extremely diverse internal and external factors, which objectively complicates the use of any methodologically universal single indicator to characterize energy dependence.

The external factors include the general state of the country's economy, including its fuel and energy complex, while the internal ones mean the country's macroeconomic indicators describing its economic activity. The combination of these conditions for a certain period of time determines the state's level of independence. A natural desire to characterize the relative state of a country by several quantitative criteria should add an objective character to such assessment. The dual nature of the country as a system that is both technological and economic leads to the conclusion that the indicator assessing energy dependence should generalize its dual nature. For this purpose, the author proposes to use the indicator Sc, which will be explained later in more detail.

The methodological foundations of the study are a systematic approach to the analysis of energy security of the European countries that have coal industry. To solve the problems indicated in the article, analytical methods and methods of structural-comparative analysis were used.

\section{Assessment of the energy security of European countries with regard to their fuel balance}

Each state today seeks to maintain its economic and energy security. In the period of 1970-1980, the countries of Western Europe experienced the energy crisis and energy price spikes of such magnitude that they had profound economic consequences. After 1989, the countries of Eastern Europe suffered from the volatility of energy markets. By 2020, due to a sharp change in oil prices, the dependence of European countries on imports of oil and gas has decreased. Typically, gas consumers in Europe bought fuel on the basis of long-term contracts. However, at present, the decrease in dependence on Russian gas and oil, the supply of 
American liquefied gas and gas from Norway significantly stabilizes the energy market in Western Europe. The 2006 predictions stated that total imports to Western Europe would increase from 35\% of natural gas consumption to $45 \%$ by 2020, even taking into account the expected significant expansion of gas production by Norway. The dependence of the CEE countries (with the exception of the Russian Federation) on imports would increase by 2020 from approximately 65 to 85\% (Commission of the European Communities, 2006).

The energy supply of European countries is constantly decreasing due to the active policy of closing coal enterprises. Yet at the same time the share of alternative energy sources is growing. In terms of supply of their own natural fuel and energy resources (FER), all countries can be conditionally divided into rich, medium and poor, which does not directly translate into the level of their financial and economic well-being. The overwhelming majority of the world countries belong to the middle tier of this classification. The countries representative of this class are Germany, Poland, Sweden, Finland, France, etc., but they also include Ukraine, which now has about $46 \%$ of its own primary FER. The countries richest in raw FER (USA, UK, Russia, Canada, Norway, oilproducing countries of the Middle East, Turkmenistan, etc.) supply more than $70 \%$ of their own demand. Almost all of these countries are energy exporters. Production in countries poor in raw FER (Japan, Italy, Switzerland, Hungary, the Netherlands, etc.) covers less than $30 \%$ of their needs, so they are forced to import a significant amount of energy resources (Commission of the European Communities, 2006).

The national-level methods of planning the optimization of the fuel and energy complex (FEC) and development of energy security and its sectors cannot reflect the complexity and diversity of local conditions, which have fundamental importance for sub-national regions of power industry - it is the latter that should ensure interconnected and balanced development of the processes of exploration, production, processing, transportation, storage and consumption of FER in the country. Therefore, complex regional problems are one of the most important subclasses of the system research in the energy sector. The key objective is planning the optimal development of regional FECs. This task is particularly important in the case of EU countries, which have highly-developed industry and agriculture but insufficient fuel and energy resources. A decrease in the country's self-sufficiency in one of these resources leads to the need for a tighter energy-saving policy. With regard to the country's FEC, the planning must involve coordinating the development of the energy base with the development of productive forces. At the same time, it is necessary to satisfy as fully as 
possible the needs for various types of fuel and energy resources of industry, agriculture, transport, housing and communal services. The country's FEC is a diversified system, and therefore its regional planning involves matching development plans for industry branches to the specifics of the country's fuel and energy base and the local consumption of FERs (Astakhov et al., 2009, p. 323).

Considering the changes on energy supply trends in European countries, it is advisable to consider the level of energy security of the states depending on coal mining, which used to be the basis of the fuel and energy complex of most European countries. However, due to global warming and drastic climate change, in recent decades coal has been gradually giving way to newly developed alternative energy sources. In terms of energy security, coal as a fuel is not safe enough. It is one of the causes of environmental pollution. Also, work in a coal mine is dangerous, harmful to health, and from a social point of view, these are early pensions, benefits for injuries, rehabilitation, regressions, etc. Currently coal industry does not attract investors, yet without this it is impossible to ensure an appropriate level of energy security. Across Europe, mines in difficult geological formations are being closed. e.g. Recently it happened to the last mine in the Ruhr basin in Germany; France, Belgium and the Netherlands closed their mines more than 20 years ago; in the UK the process of closing mines is also almost complete. Coal in Europe is still mined in Poland, Russia, and (in relatively small quantities) in the Czech Republic. Moreover, the Polish Silesian basin offers no great prospects and the production is constantly decreasing (Commission of the European Communities, 2006). However, there are still significant coal reserves in the world, and supply sources are diversified. Deliveries are made from politically stable regions. Worldwide, coal delivery infrastructure is well developed; coal can be stored, and new deliveries can be easily organized (Aland, 2013).

The experience of the first and second oil crisis demonstrated that coal prices were less responsive to the rise in oil prices than natural gas. However, even with the closure of mines, the consequences of their past activities will continue for years to adversely affect the natural environment and the population safety in the surrounding areas (Raichel \& Pavlenko, 2006, pp. 1175-1179). If the mine is to have minimal impact on the environment, the effectiveness of managing its productive flows should be monitored, taking into consideration the following factors $(C+R+G+W)$ - coal, rock, gas and water. Environmental efficiency means maintaining such balance between all factors of production (material, financial, human and others), which gives the highest degree of the consideration 
of environmental factor in the extraction and coal processing $(F)$ (Mamaikin et al., 2018, pp. 115-118)

$$
F=C+R+G+W \rightarrow \min
$$

Since all terms are positive in this equation, minimizing the sum means minimizing each of them. Minimizing the $C$ is equivalent to reducing the ash content in coal and damage from undermining to the minimum acceptable value. Minimization of $R$ means leaving the maximum possible mount of rock in the mine and minimization of surface contamination with coal mining waste. If none of the rock is moved to the surface, $R$ assumes its minimum value of zero. Minimization of $G$ means decrease in methane emissions into the atmosphere, and minimization of $W$ means decrease in the volume of highly mineralized mine water discharged into the environment (Hellmer \& Wárell, 2009, pp. 235241). All of the components of the above equation cause irreparable damage to the environment, which is contrary to the main trends in the EU's environmental development. The pattern presented above is very important in assessing the level of diversification of energy supplies (Kozachenko et al., 2003, p. 280).

Thus in the global competitive market for fuel resources, in terms of use coal certainly still occupies one of the first places. This situation is mainly due to its relatively low prices (compared with the prices of oil and natural gas). The stability of coal prices, its large deposits, and the possibility of import deliveries from many stable sources also have a significant effect as they ensure reliable functioning of power plants and other consumers who use coal as an energy carrier (Bakanov, 2015, pp. 160-167).

From the point of view of ecology and pricing environment, most countries of the European Union, proceeding from the interests of energy and national security, have transformed their fuel balances in the direction of some of the imported energy carriers - natural gas and oil products, as gas fuel is environmentally friendly and readily used.

Considering the future role of coal as an energy carrier in the energy supply of European countries, it is important to assess the main factors determining the above trends in global energy consumption. Almost every energy carrier has its technological niche, where it is used as the major or only fuel. Typical examples are petroleum products used in aviation, automobiles, and agricultural and military equipment; coke in the iron and steel industry; natural gas in everyday life and so on. These niches differ significantly in their capacity. In terms of consumption, the largest is the "oil niche": following its appearance in the 1930s, there was a rapid, almost 12-fold increase in the consumption of 
petroleum products from 450 million tons of fuel equivalent in 1940 to 5500 million tons of fuel equivalent in 2019. In a merely 30-year interval, oil share in the global energy balance grew from 14\% in 1940 to $67 \%$ in 2018 (a 5-fold increase). For all other energy carriers, niches where there are no alternatives for that carrier (or where its use clearly prevails) are much smaller. Therefore, despite the existence of these areas of predominant consumption of a specific energy source, most of the markets for particular energy carriers are competitive. In this regard, the most characteristic areas are the production of electricity and heat, where - due to modern technologies - all energy resources without exception can be successfully used (Bravard \& Morgan, 2007, p. 235).

These are the main factors that have led to the current proportions in the fuel balances of European countries, where one energy resource (natural gas), 75\% of which is imported exclusively from the territory of one country (Russia), ranks first in terms of consumption ( $45 \%$ of the total consumption of primary fuel and energy resources). In addition to their general economic potential, EU countries have a replacement reserve in the form of a "cold reserve", which is taken into service in case of failure of the main infrastructure (Brodsky, 2013, pp. 4-17). The state reserve is a sum of the reserve capacity and production capacity of its industrial and other units.

\section{Energy security indicator}

According to the definition of the "energy security", it is a combination of technological and economic components. In the modern understanding of this definition, it means achieving a technically reliable, stable, cost-effective and environmentally balanced supply of energy resources to satisfy the needs of the economy and the population; it also means creating conditions for the formation and implementation of a policy to protect national interests in the energy sector (Borisov \& Cheplyansky, 2015, pp. 115-117).

In this study, the author has developed and proposes a country energy security indicator (Sc), which consists of 3 elements. The first is an indicator of the technological reliability of industries requiring energy resources (E). The second is an indicator of the country's economic level $(\mathrm{Ke})$. The third is an indicator of the availability of mineral resources $(\mathrm{Kg})$ (Table 1$)$. The table is structured as follows: in each column, a suboptimal value of the parameter is selected, which is correlated with indicators for other countries. The resulting quotients are summarized in the energy security level column. 
Table 1. Energy security assessment of selected European countries

\begin{tabular}{|l|c|c|c|c|c|c|c|}
\hline \multirow{2}{*}{ Countries } & \multirow{2}{*}{$\begin{array}{c}\text { Non-Renewable } \\
\text { Energy Stocks } \\
\text { Per Capita } \\
\text { Dollars }\end{array}$} & $\begin{array}{c}\text { GDP per } \\
\text { capita in } \\
\text { dollars }\end{array}$ & $\begin{array}{c}\text { Energy } \\
\text { consumption } \\
\text { KWh / person }\end{array}$ & $E$ & $K_{e}$ & $K_{g}$ & \multirow{2}{*}{$\begin{array}{c}\text { Energy } \\
\text { security } \\
\text { indicator } \\
\text { Sc }\end{array}$} \\
\hline Russia & 121580 & 28797 & 6430 & 0.55 & 0.77 & 1.000 & $\mathbf{2 . 3 2}$ \\
\hline Germany & 240 & 52386 & 7215 & 1.00 & 0.86 & 0.01 & 1.87 \\
\hline France & 200 & 45893 & 7728 & 0.87 & 0.92 & 0.01 & 1.80 \\
\hline Great Britain & 5832 & 45741 & 5733 & 0.87 & 0.68 & 0.04 & 1.59 \\
\hline Ukraine & 6536 & 9287 & 3549 & 0.17 & 0.42 & 0.05 & 0.64 \\
\hline Poland & 1005 & 32005 & 3783 & 0.61 & 0.45 & 0.01 & 1.07 \\
\hline Belgium & 110 & 48327 & 8387 & 0.92 & 1.00 & 0.01 & $\mathbf{1 . 9 3}$ \\
\hline Czech & 320 & 37340 & 6321 & 0.71 & 0.75 & 0.01 & 1.47 \\
\hline Spain & 100 & 40172 & 6154 & 0.76 & 0.73 & 0.01 & 1.5 \\
\hline
\end{tabular}

Source: GDP based on purchasing-power-parity (PPP) per capita 2019.

http://www.iea.org/statistics/

Three countries with the highest level of energy security were identified Russia, the UK and Belgium (Melnik et al., 2008, pp. 63-72). Russia was selected on the account of its natural resources, while Great Britain and Belgium - due to their domestic economic potential. It should be borne in mind that Europe is forced to import almost all energy resources.

The sufficiency level of primary energy sources owned by a state describes the possibility and expediency of covering domestic energy consumption through additional supplies from outside the country, and the ability of national production structures to efficiently operate complex energy systems. The choice of this integrated indicator is explained by the fact that a high level of economic development as well as literacy and education of the population makes it possible to compensate for the lack of their own energy sources and ensure the efficient operation of complex energy production (Raichel \& Pavlenko, 2006, pp. 1175-1179).

Since the indicator of energy reliability consists of three components, what should their relation be: the sum, the product, or yet another connection? In the author's opinion, summation of the three components will be legitimate for several reasons. These two indicators have different physical meanings, but are characterized by mutual influence, so the author proposes to summarize them. To illustrate the case, the group of main coal-mining European countries was 
analyzed, and adding up the values of the constituent indices is sufficient to assess the level of their energy independence (Table 1).

\section{Diversification of energy supplies through the use of man-made waste from mines}

The concentration of monopoly power in the production and circulation of goods in different industries varies. Depending on the level of competition development in the market, the degree of concentration of firms in this market is determined in different ways. In the energy market, the predicted behavior of monopoly firms is determined with the use of the Herfindahl-Hirschman index $\left(I_{H H}\right)$ (Borisov, 2015, pp. 1168-1169, 1171). To calculate it, data on the specific weight of the enterprise's products in the industry is used. It is assumed that the greater the share of the company's products in the industry, the greater the potential for the emergence of a monopoly. When calculating the index, all enterprises are ranked by their comparative importance from the largest to the smallest. The index is the sum of the squares of each company's shares in the market for this product, arranged in descending order.

$$
I_{H H}=S_{1}^{2}+S_{2}^{2}+S_{3}^{2}+\ldots+S_{n}^{2} \text {, }
$$

What follows from the property of this indicator is that the larger the index, the greater the diversification level of specific energy consumption structures (Bardas, 2011, p. 399). If one type of primary energy is used in the country's energy balance, then the formula gives a value of zero. In the case when the fractions of several types of energy used are the same, the formula gives a value equal to $1-1 / \mathrm{n}$. With regard to the group of coal-mining countries of the European Union and in accordance with the approach reflected in equation (1), the following should be noted: the EU has approved a program to phase out coal mining and combustion in the EU. As each closed mine has a reserve in energy resources (warm water, gas, coal waste), powerful structures for distribution of heat supply to the population are needed (Heywood, 2004, p. 176).

Mamaykin (2012, pp. 115-118) proposes a system of indicators for assessing the effectiveness of outsourcing for the production of diversified products - energy from the use of mine water in heat pumps, electricity from methane combustion, the volume of gasification of residential areas, as shown in Fig. 1. 
Fig. 1. Diversified production structure post-mining

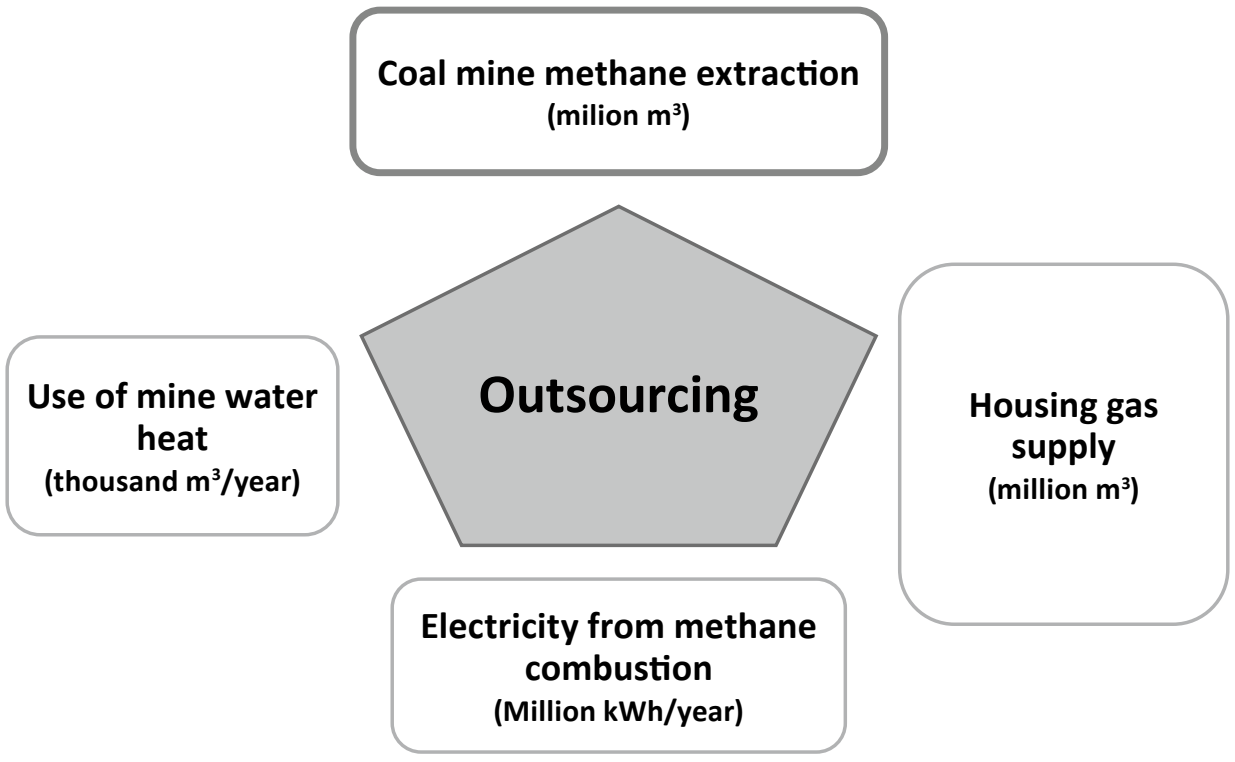

Source: author's own study.

\section{Conclusions}

Europe started to look for diversification options a long time ago, which involved gaining access to oil and gas fields. While the EU is working to implement plans of building oil and gas pipelines, Russia remains an important energy supplier. At the same time, diversification processes on the part of the EU are intensifying, which will remove Russia from its monopolistic position on the energy market. The cooperation is aimed at a mutually beneficial exchange, the consolidation of the common interests of Russia and the EU in the energy sector, and it contributes to the practical development of a common European economic space. Improving the energy supply reliability and, consequently, the energy security of Europe was ensured by changing the geography of supplies. For the European Union today, it is important to create new infrastructure capacities, as well as to search, develop and implement new alternative energy sources.

The article has focused on a group of countries producing coal and assessed the level of their energy independence. This level can affect the volume of energy supplies through the diversification of new sources of heat energy - e.g. from industrial waste. Such diversification will help strengthen and stabilize the domestic economic and environmental situation. 
Although the shift to a low-carbon economy offers many opportunities, the economic and social consequences in many coal regions should not be ignored. This is a problem especially for coal producing regions when their national economies are in transition. The current EU environmental policy has accelerated the process of crowding out uncompetitive and inefficient European coal producers by terminating EU approval of the national government subsidies which support them. Nevertheless, the research suggests that efforts should be made to investigate if a trans-European group of coal-mining countries could unite in the short term in an environmentally friendly manner to keep coal as a fuel source.

\section{REFERENCES}

Aland, F. (2013). European Energy Efficiency Policy. Retrieved from http://energohelp. net/articles

Amosha, A., \& Skubenko, V. (2015). The economic policy of the state and its impact on the activities of enterprises. Ekonomika promyslovosti - Donetsk: IEP HAH Ukraine, 1/2015, 3-12.

Astakhov, A. S., Dikolenko, E. Y., \& Kharchenko, V. A. (2009). Environmental safety and environmental management. Mining book. Moscow: Publishing House of the Moscow State University.

Baeten, G., Swyngedouw, E., \& Albrechts, L. (1999). Politics, Institutions and Regional Restructuring Processes: From Managed Growth to Planned Fragmentation in the Reconversion of Belgium's Last Coal Mining Region. Regional Studies, 1999, 247-258.

Bakanov, S. (2015). The concept of "old industrial regions" in historical and economic research: problems of theory and historiography. Magistra Vitae: electronic journal on historical sciences and archeology, 24(379), 160-167.

Bardas, A. (2011). The principles of environmental certification in the conditions of field restructuring. Dnipro: National Mining University, Institute of Economy, National Academy of Sciences of Ukraine.

Borisov, V. N., \& Cheplyansky, Y. V. (2015). Microeconomics (in 5 volumes). Vol. 5. St. Petersburg: Economic School.

Bravard, J. L., \& Morgan, R. (2007). Effective Outsourcing. Understanding, Planning and Using Successful Outsourcing relationships. Moscow: Balance Business Books.

Brodsky, V. A. (2013). Comparison of two methods for determining the boundaries of commodity markets: a test of a hypothetical monopolist and a pairwise comparison method. Modern Competition, 5(41). Available at http://www.moderncompetition. ru/e/articles/index.php?article_id_4=1529 
Bugay, S., \& Kulik, O. (2002). Depressed regions: experience of the countries of the European Union. Coal Market, 2/2002.

Commission of the European Communities. (2006). A European Strategy for Sustainable, Competitive and Secure Energy. Energy Overview: An Energy Policy for Europe. Communication From the Commission to the European Council and the European Parliament. Retrieved from http://ec.europa.eu/dgs/energy_transport /figures/pocket-book/2006_en.htm

European Parliament. (2015). Privacy and Data Protection implications of the civil use of drones. PE 519.221, 2015. Retrieved from http://www.europarl.europa.eu/RegData/etudes/IDAN/2015/519221/IPOL_IDA\%282015\%29519221

Hancher, L., Ottervanger, T., \& Slot, P. (2012). EU State Aids. London: Sweet \& Maxwell. Hellmer, S., \& Wárell L. (2009). On the evaluation of market power and market dominance - The Nordic electricity market. Energy Policy, 37, 3235-3242.

Heywood, J. B. (2004). Outsourcing: In Search of Competitive Advantage. Outsourcing Dilemma: The Search for Competitiveness. Moscow: Williams.

Kasper, H., \& Etil, B. (2012). The aftermath of the closure of the Dutch coal mines in South Limburg: Regional economic and social reconstruction. Retrieved from https://nowa-energia.com.pl/wp-content/uploads/2013/03/raport_uniwersytet_w_ maastricht_en.pdf

Kozachenko, A. V., Kozachenko, V. P., \& Ponomarev, V. (2003). Economic security of the enterprise: the nature and mechanisms of support. Kiev: Libra.

Kuznetsova, A. V. (Ed.). (2009). Regional policy of the EU countries. Moscow: Publishing House of the IMEMO RAS.

Mamaikin, O., Sotskov, V., Demchenko, Y., \& Prykhorchuk, O. (2018). Productive flows control in coal mines under the condition of diversification of production. E3S Web of Conferences, 60. DOI: https://doi.org/10.1051/e3sconf/20186000008

Mamaykin, A. (2012). Ecological Aspects of the quantitative assessment of productive streams of coal mines: Geomechanical Processes During Underground Mining. London: Taylor \& Francis Group.

Melnik, A., Shy, O., \& Stenbacka, R. (2008). Assessing market dominance. Journal of Economic Behavior \& Organization, 68, 63-72.

Melnikova, S. (2013). Decarbonization of European energy: goals and realities. Modern science: research, ideas, results, technologies, 2(13), 168-172.

Music, O. (2011). Bifurcations in nature and society: the natural science and socio-synergetic aspect. Modern high technology, 1/2011, 87-91. Retrieved from http://www. top-technologies.ru/ru/article/view?id=26640

Olszanecka, N. (2018). Russian energy sector in the face of sanctions. The Copernicus Journal of Political Studies, 1/2018, 5-18. Retrieved from https://apcz.umk.pl/czasopisma/index.php/CJPS/article/view/CJPS.2018.001/24726

Pavlenko, I., \& Trifonova, O. (2005). Vugilna mine in the aspect of targeted investment. Academic look, 2/2005, 62-66. 
Pivnyak, G., Amosha, A. I., \& Yashchenko, Y. P. (2004). Reproduction and investment processes in the coal industry. Kiev: Scientific Thought.

Pivnyak, G., Pilov, P., Bondarenko, V., \& Sally V. (2005). Internal reserves of increasing the efficiency of the coal industry in the conditions of market transformation of the Ukrainian economy. Mining Journal, 5/2005, 61-64.

Pivnyak, G., Sally, V., \& Baysarov, L. (2003). Investments in the coal industry: reality and forecasts. Coal of Ukraine, 5/2003, 4-8.

Raichel, B. L., \& Pavlenko, I. I. (2006). Objects of investments and possible sources of financing in the coal industry. In Problems of the foreign economic relations development and foreign investment attraction: regional aspect, Vol. 3 (pp. 34-37). Donetsk: DonNU.

Rozhkov, A. (2015). Structural transformations in the coal industry and regions: World experience, problems, prospects. A Collection of articles. Saarbrücken: LAP LAMBERT Academic Publishing.

Sajduk, B. (2019). Theoretical premises of the impact of artificial intelligence on international relations and security. The Copernicus Journal of Political Studies, 2/2019, 157-180. Retrieved from https://apcz.umk.pl/czasopisma/index.php/CJPS/issue/ view/1820

Trifonova, O. V. (2015). Management of sustainable coal mining enterprises operation: theory and practice: National Mining University. Dnepropetrovsk: NMU.

Voronchenok, A., Tikhomirov, A., \& Skorodumov, S. (2006). Outsourcing of high technology to create new technology. Moscow, n.p.

Zimakov, A. (2017). Is there a future for coal-fired power plants in Europe? Bulletin of MGIMO University, 5(56), 130-150. 